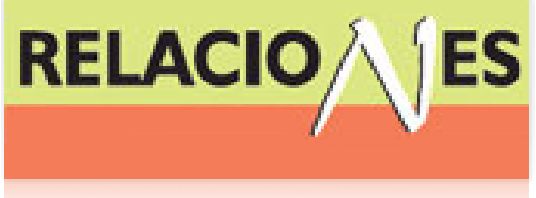

Relaciones. Estudios de historia y sociedad ISSN: 0185-3929

relacion@colmich.edu.mx

El Colegio de Michoacán, A.C

México

Castañeda García, Rafael

Un episodio del pleito entre el Colegio de San Francisco de Sales de San Miguel el Grande y el obispo Juan Ignacio de la Rocha, 1782

Relaciones. Estudios de historia y sociedad, vol. XXXII, núm. 127, 2011, pp. 119-150

El Colegio de Michoacán, A.C

Zamora, México

Disponible en: http://www.redalyc.org/articulo.oa?id=13719806005

- Cómo citar el artículo

- Número completo

- Más información del artículo

- Página de la revista en redalyc.org

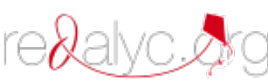

Sistema de Información Científica

Red de Revistas Científicas de América Latina, el Caribe, España y Portugal Proyecto académico sin fines de lucro, desarrollado bajo la iniciativa de acceso abierto 


\title{
Un episodio del pleito entre el Colegio de San Francisco de Sales de San Miguel el Grande y el obispo Juan Ignacio de la Rocha, 1782
}

\author{
Rafael Castañeda García*
}

UNIVERSIDAD DE GUANAJUATO

firma David Brading que a causa del asombro que desperta-
ron los sermones de Cuaresma que predicó el padre Juan
Antonio Pérez de Espinosa en San Miguel el Grande en 1712 , los principales ciudadanos de la villa invitaron al oratoriano a fundar una casa en dicho lugar. ${ }^{1}$ El espacio elegido para ello fue la iglesia de la cofradía del Ecce Homo y Ntra. Sra. de la Soledad, fundada en 1594 por mulatos vaqueros de la jurisdicción. La llegada del Oratorio modificó la vida de los habitantes de San Miguel, con la fundación de casas y templos se cambió el paisaje urbano, así como la vida religiosa y cultural. En tres décadas los padres filipenses habían fundado el Colegio de San Francisco de Sales (1734), la capilla de Nuestra Seńora de la Salud (1735), ${ }^{2}$ y dentro del templo de los oratorianos se construyó la Santa Casa de Loreto $(1736) ;^{3}$ final-

*rafauami@hotmail.com

${ }^{1}$ Entre los prósperos vecinos que apoyaron la llegada de los oratorianos se encontraron Manuel de la Canal y José de Landeta. David Brading, Una Iglesia asediada: el obispado de Michoacán, 1749-1810, México, FCE, 1994, 54. La familia de la Canal era dueña de las haciendas del Rincón, Puerto de Calderón, hacienda de Tirado. José de Landeta era criollo de San Miguel, y fue primer conde de Casa de Loja en 1753. Los Landeta eran dueños de 17 telares y de las haciendas de Alcocer y Rancho Viejo en la jurisdicción de San Miguel. El conde Casa de Loja también figuró en la política como regidor perpetuo, alférez real, y alcalde mayor de San Miguel.

${ }^{2}$ Jorge F. Hernández, La soledad del silencio. Microhistoria del santuario de Atotonilco, México, FCE, 1991, 49.

${ }^{3}$ Fundación y construcción hecha por don Manuel Tomás de la Canal en el año de 1736, Francisco de la Maza, San Miguel Allende. Su historia. Sus monumentos, México, Frente de Afirmación Hispanista, 1972, 49. 
mente en 1742, el obispo otorgó su licencia para la fundación del beaterio de Santa Ana. ${ }^{4}$

El Oratorio era una congregación de sacerdotes seculares que no hacían los votos solemnes de obediencia, pobreza y castidad impuestos a todas las comunidades religiosas, por lo tanto, se les consideraba sometidos a la autoridad de obispo. ${ }^{5}$ Desde su fundación en San Miguel, el rey otorgó la facultad a sus congregantes para poder enseñar públicamente a los nińos en escuela y a los mayores gramática, retórica, filosofía, teología escolástica y moral. Asimismo, los estudiantes de dicha casa contaron con el privilegio de poderse graduar en la Universidad de México. Fue hasta 1753 cuando de manera oficial se concedió licencia para fundar un colegio con el título de San Francisco de Sales, como obra piadosa, que tuvo como sede una casa que habían comprado con anterioridad los filipenses contigua al Oratorio, a donde acudían nińos pobres no sólo de la villa sino de toda la comarca. ${ }^{6}$

Durante este periodo surgieron centros educativos muy relevantes fuera de la sede episcopal, particularmente en la intendencia de Guanajuato: el franciscano y pontificio colegio de la Purísima Concepción en Celaya, el oratoriano Real Colegio de la Purísima Concepción en Guanajuato, y el más importante de todos, el también oratoriano de San Francisco de Sales en San Miguel el Grande. ${ }^{7}$ Como ejemplo de su importancia en la región, éste Oratorio había otorgado 156 grados de bachiller en artes en un periodo de 1744 a 1767, mientras que el Colegio de la Concepción de Celaya en un

${ }^{4}$ David Brading, op. cit., p. 62.

${ }^{5}$ Idem, p. 61.

${ }^{6}$ La venerable Congregación del Oratorio de N. P. S. Felipe Neri de la villa de San Miguel el Grande, obispado de Michoacán, expone los motivos con que ha resistido ser visitada en cuanto tal, y en cuanto Casa de Estudios, en lo respectivo a su gobierno interior económico y académico: y para no separar de sus deliberaciones al P. Dr. D. Juan Benito Díaz de Gamarra. Los dictaba el Lic. D. Manuel Quijano Zavala, abogado de la Real Audiencia de esta Nueva Espańa, y de su Ilustre y Real Colegio, impreso en México por D. Felipe de Zúñiga y Ontiveros, calle del Espíritu Santo, año de 1782, pp. 39-40.

${ }^{7}$ Carlos Herrejón Peredo, "Colegios e intelectuales en el obispado de Michoacán, 1770-1821", José Antonio Serrano Ortega, coordinador, La guerra de independencia en el obispado de Michoacán, México, El Colegio de Michoacán, Gobierno del Estado de Michoacán, Secretaría de Cultura, 2010, 54. 
lapso mucho más prolongado de 1718 a 1767, contaba con 149 estudiantes graduados. ${ }^{8}$

En la visita eclesiástica que realizó el Dr. Jerónimo Llergo, prebendario de la catedral de Valladolid, a San Miguel el Grande en 1765-1766, encontró en el citado colegio a 21 estudiantes de filosofía, 13 de los cuales contaban con becas; 10 estudiaban gramática, ocho tenían becas; y había otros 10 en sus comienzos. ${ }^{9}$ La comunidad de estudiantes de San Francisco de Sales usaba ropas de diferentes tonalidades de acuerdo a la disciplina o grado que cursaban, así, los colegiales vestían de manto morado, los gramáticos becas encarnadas, verde los filósofos, y los teólogos blancas. El colegio se gobernaba por un rector y cuatro maestros, quienes eran elegidos por la Junta General conformada únicamente por los padres del Oratorio, sin intervención del diocesano. ${ }^{10}$

Para finales del siglo xviII, la fama de este colegio se había extendido y quedaba, ante la ausencia de los padres jesuitas, como uno de los focos de cultura más importantes en el territorio novohispano. En el colegio destacó un corto pero distinguido grupo de eclesiásticos, en el que figuraba el ilustre zamorano Juan Benito Díaz de Gamarra. ${ }^{11}$ Fue durante su magisterio cuando la comunidad de San Francisco de Sales tuvo su época de esplendor. Entre este personaje y el obispo Juan Ignacio de la Rocha (1777-1782), se suscitaría un conflicto en septiembre de 1781, respecto a la jurisdicción que reclamaba el diocesano para visitar el Oratorio y su Colegio, que a su vez fue negado por los padres filipenses mediante el argumento del Real Patronato y de ser colegio meramente secular y no eclesiástico.

Uno de los temas que más polémica causó era que la congregación tenía el derecho de elegir libremente o de manera autónoma los libros que debían proponer para su enseñanza. Tiempo después éste fue uno

${ }^{8}$ Véase Rodolfo Aguirre Salvador, "Grados y Colegios en la Nueva España, 17041767”, Tzintzun, núm. 36, julio-diciembre, 2002, pp. 33-34 y 50-52.

${ }^{9}$ David Brading, op. cit., p. 62.

${ }^{10}$ La venerable Congregación del Oratorio de N. P. S. Felipe Neri, op. cit., pp. 41 y 43.

${ }^{11}$ Ernesto de la Torre Villar, "El colegio de estudios de San Francisco de Sales en la congregación de San Miguel el Grande y la mitra michoacana”, Estudios de Historia Novohispana, vol. II, 1981, 163. Entre las obras de Gamarra, Elementos de filosofía moderna, México, unAM, 1963. 
de los principales argumentos para hacer la visita eclesiástica al colegio, pues a excepción de los libros de gramática, los de las otras materias "quedan los maestros en plena libertad para enseñar, según los principios que más les acomoden y que hubieren aprendido antes". ${ }^{12}$

La transcripción del documento "Informe que hizo en la Real Audiencia de México el sr. Fiscal de Real Hacienda D. Ramón de Posada sobre un recurso de fuerza ${ }^{13}$ en el negocio de los PP. Filipenses de San Miguel el Grande con el obispo de Michoacán", "14 está fechado en marzo de 1782 y es parte de todo un cuerpo documental que aborda el conflicto entre el obispo Rocha y el Oratorio iniciado en septiembre de 1781, cuando el prelado firmó un decreto oficial en que anunciaba que efectuaría una visita a la congregación y a su colegio.

Si bien, años antes el Oratorio había recibido la visita de otros obispos y sus delegados, ahora aseguraban tener de la Santa Sede la exención para no ser visitados en cuanto gobierno interior y económico. Un hecho en particular desató que los padres se negaran a la visita, sucedió en Lima en 1758, cuando la Santa Sede eximió de toda visita episcopal al régimen interno del Oratorio. El padre Gamarra argumentó que la Bula de la erección del Oratorio de San Miguel tenía idénticas las cláusulas que las del Oratorio de Lima, por lo que le solicitó al obispo los declarará exentos de la visita eclesiástica. ${ }^{15}$

${ }^{12}$ Ernesto de la Torre Villar, op. cit., p. 169.

${ }^{13}$ Es un recurso jurídico por medio del cual el poder temporal puede revisar las actuaciones de las autoridades eclesiásticas. Dependía en América de la Real Audiencia. Véase el documento adelante.

${ }^{14}$ El documento se localizó en la Biblioteca de Castilla-La Mancha, colección Borbón-Lorenzana, Varios papeles, manuscritos, tomo 16, 1772-1790, fojas 351-369.

${ }^{15}$ Informe por la jurisdicción eclesiástica del obispado de Valladolid de Michoacán, en el recurso de fuerza, que han introducido la Venerable Congregación del Oratorio de San Felipe Neri de la villa de San Miguel el Grande de dicho obispado: suponiendo habérsela hecho el doctor don Joseph Pérez Calama, arcediano dignidad de aquella santa iglesia, como visitador general del mismo obispado por el R. obispo difunto, Dr. y Mro. D. Juan Ignacio de la Rocha: en haber pretendido visitar el gobierno económico y académico del Colegio de Estudios de San Francisco de Sales, (en los términos que siempre se habia practicado, sin la menor contradicción, ni protesta) que es a cargo de dicha Congregación: para que esta Real Audiencia se sirva decir no hace fuerza el visitador en visitar dicho Colegio: como ni tampoco haberla hecho el citado R. Obispo en los demás puntos, sobre que la misma Congregación extendió después su recurso. Por el Dr. D. Joseph Nicolás de Larragoiti, presbítero del mismo obispado, colegial del Real y más antiguo de S. Ildefonso de esta Corte, Catedrático Regente de Decre- 
Las preguntas planteadas por Ernesto de la Torre Villar muestran la dimensión del problema y lo que seguramente pensaba el diocesano en turno:

¿Cómo podía oponerse una Congregación a la visita pastoral que su misión le imponía? ¿Cómo un representante de la Santa Sede y del monarca en virtud del Real Patronato, podía ser impedido de ejercer sus obligaciones, bajo el pretexto de estar la Congregación por sus constituciones exenta de toda intervención en su gobierno espiritual y temporal, económico y político? ¿No acaso tuvieron que doblegarse a la política regalista las órdenes religiosas y aún la misma Compañía de Jesús? Estos pensamientos fueron los que movieron al mitrado michoacano y a su promotor fiscal don José Joaquín de Eguía y Muro a enviar al arcediano don Joseph Pérez Calama como visitador general del obispado, a efectuar la visita de el gobierno económico y académico del colegio. ${ }^{16}$

El 3 de diciembre de 1781, Pérez Calama estaba frente a las puertas del colegio de San Francisco de Sales para inspeccionarlo, nuevamente el padre Gamarra enfrentó la situación, ${ }^{17}$ permitió el acceso a la capilla, pero se negó a entregarles las cuentas del colegio, ya que éstas pertenecían a su "gobierno económico y interior" en el cual no tenía jurisdicción el obispo. La situación llegó al extremo de amenazar a los oratorianos que estaban en peligro de excomunión, y para confírmalo les suspendió la licencia de administrar los sacramentos. ${ }^{18}$ Los cauces legales iniciaron, el Oratorio informó el 3 de enero que ya había presentado una apelación legal, conocida técnicamente como recurso de fuerza ante la Audiencia real de México, la respuesta fue inmediata, el obispo ordenó excomulgar a 10 sacerdotes del Oratorio. Esto no era un hecho menor, la sociedad sanmiguelense

to de esta Real, y Pontificia Universidad, y su Consiliario, Abogado de esta Real Audiencia, y de su Ilustre, y Real Colegio, como apoderado del Promotor Fiscal de aquella diócesis. Impreso en México, por D. Felipe de Zúñiga, y Ontiveros, calle del Espíritu Santo, año de 1782, pp. 17-18.

${ }^{16}$ Ernesto de la Torre Villar, op. cit., p. 166.

${ }^{17}$ Tenemos, frente a frente, dos de los mayores exponentes de la Ilustración mexicana. Calama fue nombrado en 1788 obispo de Quito.

${ }^{18}$ David Brading, op. cit., p. 67. 
veía con buenos ojos a los filipenses, por tanto había la posibilidad de desatarse un motín, por lo que el siete de enero fue levantada la sentencia a los padres. ${ }^{19}$

Finalmente, el 3 de enero de 1783, la Audiencia declaró que los actos del obispo como visitador, constituyeron una intromisión injustificada en los derechos del Oratorio. Se aceptó que el breve papal de 1758, emitido para resolver la disputa en Lima, se aplicaba a todos los oratorios y por tanto los eximía de toda visitación episcopal, pero este fallo no incluía al colegio, por lo que el Oratorio envió a la Corona una petición de reconocimiento de la condición secular de su colegio. ${ }^{20}$

El documento presentado es parte de esta disputa, y tiene como principal argumento demostrar que el colegio es meramente secular, y por tanto independiente de la jurisdicción eclesiástica. Para la fecha en que fue escrito, marzo de 1782, el obispo Rocha ya había fallecido en una hacienda cercana a San Miguel en febrero del mismo año. Por su parte, el otro protagonista, el padre Gamarra murió en noviembre de 1783, a la edad de 38 años. Para Ernesto de la Torre Villar, este pleito no representó un simple caso de competencias ni jurisdicciones, sino el deseo, por parte del mitrado, de mantener la ortodoxia y la obediencia política en la provincia, evitando la creación de focos ideológicos que en alguna forma pudieran alterar la pureza de la fe y el acatamiento de la legítima autoridad. ${ }^{21}$ Hecho que más tarde sucedería con la guerra de independencia iniciada en 1810 en el Bajío novohispano.

Otros puntos son dignos de notas: en ese momento de "Ilustración" tenemos de cada lado de la barrera (defendiendo la autoridad o la autonomía) a Calama y Gamarra, dos lumbreras de esa misma ilustración novohispana. Y detrás está el regalismo modernizador y autoritario que usa uno contra otro. Inclusive el poder temporal se apoya, mediante el procedimiento de recurso de fuerza, sobre una decisión pontificia, cuando la misma Santa Sede rehusa ese recurso

\footnotetext{
${ }^{19}$ Idem, pp. 67-68.

${ }^{20}$ Idem, p. 71.

${ }^{21}$ Ernesto de la Torre Villar, op. cit., p. 168.
} 
procesal: como en muchos juegos de poder hay algo de perversión, o por lo menos de ambigüedad.

Ambigüedad que por lo demás se respalda, por un lado, sobre la gran flexibilidad que ofrece la casuística: en este caso se apela a precedentes de otros siglos, otros lugares (Guadalajara, Virreinato del Perú...). Por otro lado, se usa de un instrumento de coerción fundamental: el Real Patronato. En materia eclesiástica éste puede torcer todo: "aunque se pugna toda servidumbre de lo espiritual a lo temporal, se tolera la que empezó en cosa profana y después logró espiritualizarse", dice el fiscal de la Audiencia de México en el texto. El drama de la época es que hasta lo espiritual se está secularizando: en esto el Patronato tiene gran responsabilidad y el documento lo aclara.

\section{TRANSCRIPCIÓN DEL DOCUMENTO}

Año de 1782

En el negocio de San Miguel el Grande informó en la Real Audiencia el Sr. D. Ramón de Rosada en los términos siguientes.

\section{Señor}

El fiscal no molestará a V. A. con la repetición de los hechos de la causa. No referirá los principios de tan ruidosa controversia, su progreso, ni se detendrá a exponer su juicio sobre las reciprocas particulares pertenecientes de las partes.

Manifestará sencilla y brevemente porque no puede tener lugar el Recurso de fuerza en este caso, y los principales fundamentos de la Regalía del Patronato que se ha propuesto defender.

En dos maneras pueden venir a V. A. los pleitos eclesiásticos por vía de fuerza. La primera cuando un juez eclesiástico, ordinario, apostólico, o conservador procede contra algún lego sobre causa profana absolutamente, y el lego declina su jurisdicción, quejándose, de que proceda contra él, o se pronuncie por su juez.

La segunda: cuando los jueces eclesiásticos proceden entre personas eclesiásticas, y de la sentencia definitiva o de otros autos apelan para el superior, y no se les quiere otorgar la apelación, en cuyo caso, ocurriendo por vía de fuerza, también conocen las Audiencias. 
Ambos recursos están prescriptos en las leyes. Una de Castilla dice así: "Por cuanto nos pertenece [alzar] las fuerzas que los jueces eclesiásticos hacen en las causas eclesiásticas de que conocen, en no otorgar las apelaciones, que de ellos se interponen: y así mismo prohibir que no conozcan los tales jueces eclesiásticos contra legos sobre causas profanas. Por ende mandamos a los dichos nuestros jueces, que quejándose ante ellos de los dichos jueces eclesiásticos... en no les otorgar apelación legítima, y de que conocen contra legos sobre causas profanas les manden, que otorguen las dichas apelaciones, y que no conozcan de las dichas causas profanas contra legos, y las remitan a los jueces seglares que de ellas deben conocer \&sa”.

De esta ley muy clara y terminante se deduce, no poderse declarar que el visitador hace fuerza en no otorgar. Falta que la congregación se queje, según aquella expresión, quejándose ante ellos de los dichos jueces eclesiásticos en no les otorgar la apelación: palabras inductivas de condición y necesidad de queja, la cual ni hay, ni hubo aunque también se haya interpuesto al fin apelación al Metropolitano.

No puede tener lugar el recurso de conocer, y proceder, o Auto de legos. Este pide que el juez eclesiástico conozca contra legos sobre causas profanas, y ni los P. P. de la congregación de San Felipe son ni se tendrán por legos, ni han dicho jamás que la causa sea profana, sino que es conexa, e inseparable de la visita del gobierno interior de su congregación, que estimarán precisamente por cosa Eclesiástica, y acaso espiritual.

Se infiere pues, que no puede tener lugar el recurso de fuerza intentado en conocer, y proceder, y que está mal dirigido en la forma y términos en que se introdujo. No se procede contra legos. La excepción opuesta en razón de causa, lejos de enervar y resistir la jurisdicción episcopal, le abre campo, y da lugar.

Pero aunque esto así sea pudiera tenerle sin embargo por otras consideraciones. En medio de lo que se ha dicho, la causa es profana y secular. Su conocimiento propio del Patronazgo Real. Cualquiera otra jurisdicción, que quiera visitar el Colegio de estudiantes jóvenes de San Francisco de Sales de la villa de San Miguel el Grande perjudica la regalía. Un colegio meramente secular, no puede ser visitado por la jurisdicción episcopal. 
No por eso hará fuerza, por ahora, el visitador en conocer y proceder. Era preciso para esto que insistiese en visitar. Entonces el fiscal promovería el recurso conveniente. Entre tanto no tiene el negocio estado para la declaración de fuerza.

Aún después de librada la ordinaria al visitador a pedimento del fiscal podría aquel evitar una declaración siempre sensible. En la provisión se manda al eclesiástico no conozca siendo el que se querella lego y reo; la causa mere profana, o de la suprema regalía: que pase el mismo proceso al juez seglar, que del pueda, y deba conocer: y que de no hacerlo así lo remita a la Audiencia original.

Si en virtud de esta provisión el juez eclesiástico se inhibe del conocimiento de la causa no hay para que la envíe a la Audiencia, cumplida la una parte que se manda.

De aquí es, que el estado del negocio presente no es el que debiera ser para una declaración de fuerza, bien que no por esto podrá dejar de remitirse desde luego al Vice patrono, o juez seglar según la ley se explica, que del pueda y deba conocer.

Quien sea este, lo expresa claramente aquel capítulo especial de la Instrucción de los virreyes en que se les manda "tengan muy particular cuenta con la conservación del derecho del Patronazgo Real, haciendo que los prelados eclesiásticos le guarden y no se metan, ni embaracen en lo que no les pertenece como algunos lo han intentado, poniendo en ello el cuidado, desvelo, y atención que conviene, para que el Real Patronazgo en ninguna provincia, ni con ningún pretexto pueda ser perjudicado, ni ofendido".

Un autor de lo más celebres, no dudó asegurar que este cuidado y jurisdicción concedida en los primeros tiempos a las Audiencias Reales para determinar y dirimir las causas del Patronazgo Real, se trasladó después a sus presidentes y virreyes de manera que en ellos resida hoy privativamente el ejercicio, disposición y administración de este Real Derecho, con el conocimiento de sus causas.

Y aunque esto se veí practicado, y solidamente establecido, no será importuno hacer presente la dificultad que hay para mezclarse en tales puntos las Audiencias aún por vía de fuerza.

Una ley prohíbe señaladamente estos recursos en las causas, y 
casos de sacerdotes removidos de las doctrinas, conforme al Real Patronazgo de acuerdo de los virreyes y prelados.

La cédula dirigida en el siglo pasado a la Audiencia de las Charcas, con motivo de la contradicción que hizo su fiscal a que diese la colocación de un curato del corregimiento de Chayanta al licenciado Diego de Orellana Manos alvas, extiende más esta doctrina.

La audiencia, llevado a ella el negocio por vía de fuerza, declaró hacerla el cabildo en sede vacante que le quería dar la colación, pero visto en el Consejo de las Indias, se extrañó que la Audiencia se hubiese mezclado en esto, no tocándola; pues caso que se hubiera de hacer algún reparo, o contradicción, había de ser ante "el Presidente, como persona que ejerce el Patronazgo".

Estas expresiones prueban: lo primero: que el vice patronato reside solamente en las personas de los presidentes y virreyes. Lo segundo, que el fiscal de aquella audiencia debió contradecir ante el Presidente y no en otra alguna parte. Lo tercero que sin embargo de no tratarse en este caso de doctrineros removidos, no pudo la $\mathrm{Au}$ diencia mezclarse, ni por vía de fuerza en él por ser del Patronazgo.

No recibe menos claridad tan dificultoso punto de otra más reciente Real declaración.

Recayó en el hospital de los P. P. betlehemitas de la ciudad de Guadalajara, que es de Patronato Real una capellanita ocurrieron los religiosos al Vice Patrono Presidente demandando réditos, y principal contra las hipotecas, estando éstas concursadas en el Juzgado Eclesiástico por el pago de unas dotes.

El Vice Patrono dio comisión para proceder al embargo, no pagando; pero el ordinario puso en Tablillas al comisionado y no obedeció los repetidos exhortos del presidente, para que se absorbiese y se inhibiese del conocimiento, y dudando en poner la pena de temporalidades, consultó al Virrey.

El Fiscal de esta Audiencia fue de parecer que el Virrey, no podía dar auxilio usando de Provisiones en el Real nombre; pero interpuesto por el fiscal de la de Guadalajara el recurso de fuerza en conocer y proceder; se dijo hacerla el eclesiástico.

Lo aprobó S. M., y al mismo tiempo por Real Cedula de 19 de octubre de 1756 se dignó declarar que los Vice patronos y los Virre- 
yes como tales en uso del Patronato Real pueden despachar Provisiones en el nombre Real, y con armas Reales, imponer las penas establecidas por las leyes.

Lo segundo (que hace más a nuestro caso) que en materia de Patronato, ni puede el eclesiástico declararse juez, ni ofrecerse competencia, ni recurso de fuerza, que no debía haber habido en el caso propuesto, tratándose de interés de un Hospital del Real Patronato; pues aunque la cantidad demandada, no era dotación Real, una vez adquirida por el Hospital, había tomado su naturaleza e investidura, y seguía sus reglas y jurisdicción, siendo la de los Vice Patronos, privativa y absoluta.

Ni esto se compone mal con aquéllas cláusulas en que otras leyes mandan a los Virreyes, Audiencias y Justicias Reales proceder con todo rigor contra los que faltan a la firmeza y observancia del Patronazgo, poniendo en ello la diligencia necesaria.

La práctica y las resoluciones posteriores han separado y distinguido las funciones y facultades respectivas, y aún queda a las Audiencias el acto de impartir el auxilio para los extrańamientos, y ocupación de temporalidades, cuando los Vice Patronos se le pidan porque así lo juzgan conveniente para proceder con más seguridad, pulso y detención en materia tan ardua, tan escrupulosa y delicada. Ello es que en otros testimonios no puede mezclarse en otros asuntos las Audiencias, no tocándolas que el fiscal caso de estimar deberse hacer contradicción, debe hacerla ante el Virrey, como persona que ejerce el Patronazgo, y que la Real Cedula del 19 de octubre de 1756 no permite el recurso de fuerza que se ha interpuesto ahora, contraviniendo a su disposición derechamente.

Más como proceda el discurso en el supuesto de que esta materia se haya contenida dentro de la esfera y límites de la Regalía del Patronazgo, no dejará de convenir dar algunas pruebas de proposición tan ciertas y sólidas.

Una ley de partida describe así las Regalías. Son cosas que están ajuntadas siempre al señorío del Reino y un escritor sabio teniéndola presente dice: "que son ciertos derechos propios del rey, clavados en sus huesos, como señal de la superioridad y del dominio.” 
Todas las reglas con que se dirigen y gobiernan otras Regalías, todas sin faltar una se acomodan a la del Patronato Real pero principalmente aquélla que es, como su divisa que no puede nunca separarse de la Real Corona.

Esto es lo que primeramente ordena la Ley de Indias que este derecho de Patronazgo único e in solidum sea siempre reservado a la Corona, y no pueda salir de ella en todo ni en parte, ni por gracia, merced, o privilegio, ni por otra cualquier disposición: en que se hecha de ver el aprecio singular que ha merecido siempre a nuestros soberanos y aún por eso han dicho algunos, que esta Regalía, Señorío Real honra, o Mayoría del Patronato brilla y sobresale entre todas las demás.

Del cuidado y particular esmero que se ha puesto siempre en su conservación hoy provenido, que aunque los tribunales eclesiásticos que conozcan de las causas o controversias que se suscitan en los particulares Patronatos, nunca han conocido de las del Patronato Real, cuya determinación ha sido en todos tiempos de los tribunales Reales.

Pero observándose que de conocer de esta Regalía en el Consejo Real, Chancillerías, y otros diversos tribunales, aún parecía mucho ya por no hallarse los papeles cuando era menester, y ya porque de andar en tantas manos se seguían otros inconvenientes de consideración, se mandó que todos los negocios de esta clase de cualquier calidad que fueren se viesen y se determinasen precisamente en el, Consejo de la Cámara inhibido hasta el mismo Consejo Real de entrometerse en ellos en ninguna forma.

Habiéndose dudado alguna vez, si este o aquél negocio era o no perteneciente al Patronato, y por consiguiente que tribunal era incompetente se determinó así mismo que sólo el pedirse o pretenderse por alguna de las partes, o por el fiscal o otra persona, ser del Patronato bastaba para que se conociese en la Cámara y se tuviesen por inhibido el consejo y otro cualquiera tribunal.

De esta práctica establecida al principio del siglo pasado en aquella Cédula célebre, dada en Martín Muñoz, confirmada por otras declaraciones posteriores, se infiere que en los asuntos del $\mathrm{Pa}$ tronazgo Real, no quiere el Rey que conozcan muchos tribunales, 
aunque sean muy altos, muy llenos de reputación y autoridad, porque tratándose por muchas vías o manos los negocios, ni pueden estar prontos los papeles ni dejar de tocarse otros inconvenientes de consideración: y estando ya notado arriba lo que se ha estimado suficiente en razón de la jurisdicción en estas materias de los Presidentes y Virreyes, esto puede servir de mayor comprobación de ser su conocimiento privativo.

Esta declaración también conduce para evitar competencias y dificultades sobre la calificación previa de ser o no el asunto perteneciente al Patronato. Basta, según ella que el fiscal lo diga para que el Virrey conozca, así como basta, para que conozca allá la Cámara.

Pero el Fiscal no pretende tanto. No quiere, aunque pudiera pedir, que sea creído sobre sola su palabra. Expondrá brevemente las particulares circunstancias que constituyen la visita y el gobierno del Colegio de Sales asunto del Patronato Real, y uno de aquéllos en que tiene interés más inmediato.

Llamase estudio "aquel Ayuntamiento de maestros y de escolares que es hecho en algún lugar con voluntad o entendimiento de aprender los saberes. Los omes, dice la ley de partida e las tierras, e los reinos, se aprovechan, e se guardan e se guían de los omes sabios" por eso la erección y fundación de Estudios se ha estimado siempre perteneciente a la facultad política, profana y propia de los príncipes.

Los nuestros criaron y fundaron en las Indias Estudios generales para desterrar la ignorancia para servicio de Dios y bien público de estos fidelísimos vasallos, por el mucho amor y voluntad de honrarlos y favorecerlos.

Los fundaron y erigieron sin autoridad eclesiástica ni pontificia. Esta insigne universidad florece y fue tan propio y verdadero estudio desde el año de 1553, en que se erigió como después del año de 1595 en que se confirmó por el Sumo Pontífice. La de Salamanca se fundó en el de 1200, y nadie ha dudado que fuese estudio general antes de la confirmación de Alejandro IV en 1255.

$\mathrm{Ni}$ estos establecimientos seculares y profanos pueden nacer, sino debajo de la sombra y facultad expresa de los reyes: facultad, gracia o licencia, que se considera, y es un favor, y un beneficio insigne de que deriva el Patronato en las iglesias, universidades y colegios. 
El interés y la conveniencia suma que resulta al Estado, de su conservación, método y buen orden da a los príncipes aquellos derechos altos de custodia, defensa, cuidado y protección, que sin requerir dotación, ni donaciones, forman la verdadera y natural esencia del Patronato Universal.

Cuando concurre todo, como en esta Real Universidad o los fundadores o patronos particulares ceden al rey el derecho que adquirieron, de que también hay en las leyes ejemplares, concurre en S. M. el Patronato Universal, el honorífico o general, y también el particular, el privativo y específico.

Pero no siempre obran unos constantes efectos el Patronato Real Universal, ni el específico. Aquel induce a veces una exclusión total del concurso de otra jurisdicción, hay veces no hay caso en que sin embargo del Real especifico, o particular el gobierno y administración de las fundaciones patronadas, pertenece privativamente a los prelados.

Y aunque apenas se puede dar una regla fija y general, si se consultan las diversas repugnantes y contrarias opiniones es común sentir que la causa de Estudios, es puramente temporal. Que el príncipe tiene intención fundada en su territorio y más que en otros en el de Indias: y que siempre se ha de estar a la presunción que hay a favor de su jurisdicción, si no se prueba exención particular.

Pero más que las disputas y diferencias escolásticas, más que las sentencias voluntarias de algunos que han fatigado las prensas para copiarse, impugnarse o contradecirse, tal vez sin otro apoyo ni razón que la autoridad de otros semejantes, debe influir para la comprensión y decisión de esa materia esa Cédula Real citada y repetida que dichosamente la esclarece.

El Colegio Mayor de Santa María de Todos los Santos, que para lustre y ornato de esta capital, bien y gloria de la Nueva España fundó el año de 1573 Don Francisco Rodríguez Santos dignidad de su Santa Iglesia Metropolitana, se quejó a V. A. a principios de este siglo del M.R. Arzobispo que entonces era y de sus procedimientos en un recurso que de los de su Rector interpuso uno de sus colegiales.

Habiéndose declarado, que en conocer y proceder en dicha causa el M. R. Arzobispo, no había fuerza, se expidió por mandato del 
señor Don Felipe V con fecha de 11 de junio de 1709 la Real Cédula citada, en que considerando el grave perjuicio de su regalía y su indubitado derecho del Patronato Universal en los Reinos de las Indias y en todos los colegios y seminarios meramente seculares (son palabras de la Cédula) y tener S. M. por esta razón la jurisdicción en todo lo perteneciente a su gobierno económico, se extrañó con graves demostraciones la declaración referida, como notoriamente perjudicial a la Regalía del Patronato, por no poderse entrometer en nada la jurisdicción eclesiástica en los colegios, no constando ser eclesiásticos legitima y con concluyentemente.

Esta Real resolución que contiene aquella cláusula notable de que se registre en el libro de Acuerdos, para que se observe y guarde en todos tiempos, impone en esto mismo la necesidad de tener siempre presentes sus declaraciones generales, como segura pauta y ley.

Prescindiendo del negocio particular que la causó, y de sus especiales circunstancias, porque ni se tiene a la vista ni se necesita, no puede disputarse que esta Real Declaración es a lo menos para V. A. una ley cierta, de cuyas partes jamás podrá desentenderse.

El fiscal después de haber seriamente meditado esta Real Cédula, haya en sus palabras mismas expresamente decidido: lo primero, que el Rey tiene el derecho de Patronazgo en todos los reinos de las Indias en los seminarios y colegios meramente seculares.

Lo segundo: que por el mismo derecho de Patronato Universal, tiene $S$. M. jurisdicción en todo lo que diga relación al económico gobierno de ellos.

Lo tercero: que en esta jurisdicción en todo lo económico lejos de ser acumulativa, la jurisdicción eclesiástica en nada puede entrometerse en los colegios meramente seculares.

Lo cuarto: que la jurisdicción eclesiástica puede conocer y ejercerla en los colegios que constare ser eclesiásticos, legítima y concluyentemente.

Estas proporciones deducidas, no del espíritu, ni de la mente de la ley, sino de sus mismas claras y puntuales expresiones, son la mejor y más evidente apología del Patronato en la presente controversia, y hacen lugar a más ilaciones innegables. 
Porqué ¿Quién podrá negar, que si el Colegio de San Francisco Sales de la villa de San Miguel el Grande, es un colegio meramente secular, es del Real Patronato universal? ¿Qué por este Patronato toca al rey entender en lo económico de su gobierno? ¿Qué la jurisdicción eclesiástica en nada puede entrometerse de lo que pertenezca a este Colegio? ¿Qué en el sólo caso de que constase legítima y concluyentemente ser el Colegio de San Francisco de Sales, eclesiástico podría mezclarse la jurisdicción eclesiástica en su economía y su gobierno? Resta pues únicamente demostrar que este colegio no es eclesiástico sino meramente secular.

Algunos cuerpos se dicen eclesiásticos por razón de orden o de estado, como las iglesias, catedrales, las colegiatas, y conventos religiosos, y también lo son aquellos en que los obispos interpusieron su autoridad, no sólo con el fin de hacerlos [hitos], sino con el de espiritualizarlos, así como se ve con las capellanías colectivas, algunas cofradías de legos, y colegios.

Pero falta toda autoridad eclesiástica toda solemnidad e intervención en la fundación, formación y erección de San Francisco de Sales.

El reverendo obispo que era de Valladolid en el año de 1753 en que se fundó, no tuvo otra parte en este asunto, que haber informado al gobierno favorablemente en razón de su utilidad, y conveniencia: y si después le han visitado los Prelados sucesores con el loable y santo objeto de reformar los desordenes que el tiempo pudiera haber introducido, son estos unos actos, que sobre no poder perjudicar, ofender, ni determinar en parte alguna el derecho imprescriptible de la regalía, no han alterado transformado o elevado, ni aún de hecho, la esencia o la naturaleza del colegio, como muy fácilmente se prescribe el cotejo de su estado actual con el de sus principios, y creación.

Se dice, ni aún de hecho, porque sin el ascenso de los Reyes, ni los Pontífices pueden aunque quieran eximir los estudiantes legos de su jurisdicción, ni aunque hubiera habido en la fundación de este Colegio o posteriormente, la aprobación y autoridad episcopal, podría este sobre añadido mudar su condición primera, al modo que la gracia apostólica concedida para ampliar o mejorar algún 
derecho secular, se deja usar como temporal y se acomoda a su naturaleza lejos de alterarla.

Por esta razón aunque repugna toda servidumbre de lo espiritual a lo temporal, se tolera la que empezó en cosa profana y después logró espiritualizarse: no habiendo parecido justo, que esta circunstancia prive del dominio, libre, secular al que antes le tenía, como se ve en los vasos y vestiduras sagradas en un Oratorio, en que el dueño de la materia le conserva plenamente sin embargo de la cualidad que sobrevino.

Así, aunque por haber formado y aprobado las constituciones o en otra manera, hubiera intervenido aquella autoridad episcopal necesaria para hacer Eclesiástico el Colegio de San Francisco de Sales, alterando su naturaleza, todavía se debería defender, que sin el expreso consentimiento Real no se habían eximido sus estudiantes legos de la jurisdicción secular ni se había privado al dueño soberano de la Regalía de alguno de aquellos derechos que antes le correspondían por razón de la conveniencia pública y adorno de la majestad.

Los colegios pues que nada tienen de eclesiásticos no podrán dejar de ser meramente seculares y también los que se componen de seculares en la mayor parte; pero serán eclesiásticos si tienen igual o mayor número de clérigos que de seculares.

Esta distinción aunque generalmente recibida no agrada porque en la última parte tiene contra sí razones de muy grave peso; más la trae el fiscal en cuanto conduce a dar idea del modo de pensar de los pragmáticos.

Ellos la han adoptado y referido como comunísima, y el fiscal la admite en lo que no le perjudica, porque siempre prueba que es colegio mere secular aquel de que se trata, componiéndose todo el de seculares y no exigiendo por fundación que alguno de sus individuos sea eclesiástico.

Pero no puede omitirse una dificultad, que nace del modo en que algunos han entendido esta sentencia, que dicen tiene lugar, cuando los colegios son instituidos absolutamente para estudios; pero no, si lo refieren para estudio de jóvenes pobres, como el de San Francisco de Sales: en cuyo caso, por razón de causa piadosa, 
puede el obispo mezclarse por contravención o negligencia, y para esto visitar y examinar ¿si se cumple o no como se debe lo que los fundadores han querido? Al modo que visita los testamentos, aunque sean de testadores legos, y los albaceas y herederos seculares.

No se niega ni disputa el singular cuidado y atención con que las causas piadosas deben ser tratadas; pero no por esto se debieron haber esparcido en volúmenes enteros, privilegios que no tienen, ni tampoco necesitan; ni hay razón para que al paso que no ha quedado cosa que no se haya hecho causa de piedad, se entiendan respecto de ellas, abrogadas las leyes, fueros, o derechos que tanto trabajo y tiempo ha costado establecer dando por consecuencia una extensión tan indefinida y arbitraria a la jurisdicción episcopal cual no han querido ni pretendido ejercer nunca los obispos conociendo bien su inutilidad y exorbitancia.

No solamente se ve impreso, que es causa piadosa, lo que se ha dejado a iglesia o monasterio; sino también lo que a un monje en particular, a una viuda, o un huérfano.

Se sostiene, que es legado pío la libertad que se dejó a un esclavo la manda que hizo un testador para que se paguen deudas, aunque sean ajenas: para reparar caminos, componer puentes, limpiar un foso, levantar un muro.

Cuanto se dirige a la utilidad pública, o se puede constituir en la razón de bueno todo se dice PIO: sujeto al conocimiento de la jurisdicción eclesiástica libre de las imposiciones de los jueces seculares y de todas las canónicas, que no dimanen inmediatamente del derecho divino o natural.

Confiesan los A. A. de estas opiniones, que en las tierras del imperio y de los reyes y en los negocios seculares, se deben guardar las leyes civiles y reales. Pero niegan su valor en los legados ad pías causas.

Habiendo institución pía cualquiera testamento, aunque imperfecto, rompe el primero más solemne: la firma sola del testador sin testigos, vale como el más perfecto testamento. Las mujeres son testigos idóneos en estas últimas disposiciones: aunque sean imperfectas, por el defecto de solemnidad, y lo que es más de voluntad subsisten como las más completas y acabadas. 
De cualquier manera que conste de la voluntad del testador, sea por indicios, sea por señas, aunque sea ciego, sordo y mudo desde el nacimiento: aunque no haya fecha, todo es bueno y valido, en habiendo de por medio causa pía.

Por favor suyo, se puede sustituir directamente al púbero, aunque tenga la herencia ya aceptada: y un indigno o ilegítimo que no puede ser instituido por derecho lo puede ser desde el momento que entro en un monasterio porque es lugar piadoso.

La porción canónica, la cuarta parroquial, la episcopal: la falcidia: la trebeliánica, no tienen lugar en estos casos.

Aquellas palabras generales de urbanidad y complacencia dirigidas a una persona que se quiera honrar y distinguir, $\underline{\mathrm{Vm}}$, pueda hacer de mis bienes lo que le parezca cuanto hay en mi casa es de Vm, no obligan, ni disponen, sino cuando la causa piadosa le conviene.

Abusaría el fiscal de la benignidad de V. A. si quisiere referir todo lo que los A. A. que corren y se citan como acuerdos, de mucha autoridad y graven nota han esparcido en sus discursos, lo que ha compendiado de bastante idea del escrúpulo, circunspección y desconfianza con que deben ser leídos; y porque no se crea, que estas proposiciones se han tomado de autor desconocido, se referirá una que el docto canónigo don Juan Gutiérrez juzga por cierta y defendible.

Afirma, pues, que el obispo puede pedir las cuentas de las alhóndigas, rever las tomadas por los administradores, si están buenas aprobarlas sino reformarlas y dar providencias para que en adelante se guarden los estatutos y constituciones de estos públicos depósitos.

Funda la jurisdicción o intendencia episcopal el que el fin de semejantes establecimientos es alimentar los pobres y el común de la república, que es causa de piedad y ańade: que esto es en su juicio, y pudiera haber dicho que también lo era en el de otros que tratando de los legados para fortalecer ciudades dicen que son piadosos, porque de aquí resuelta la custodia de las viudas que están dentro.

Unas proposiciones tan extravagantes, como perniciosas, despreciadas altamente de los que pudieran tener más interés en adoptarlas, son la mejor prueba que se puede dar de la necesidad que en las materias legales hay de buena crítica y principalmente de no perder jamás de vista las soberanas decisiones. 
Ellas son las que deben examinarse atentamente, y las que tal vez se ven lastimosamente preferidas de una opinión de Gutiérrez, Firaquello, Bartolo, o de otro jurisconsulto semejante, por no advertirse la infinita diferencia que hay entre la declaración de un Príncipe y la interpretación particular.

Hay tanta, como entre lo cierto, y lo de indeterminado: entre lo Real, y lo aparente: entre la ley sólida y el ligero discurso de los hombres: las opiniones en su principio falsas o que se reprueban como tales caen por fin con cuanto se había edificado sobre su cimiento débil y las conclusiones que de grado en grado se habían ido deduciendo por ociosidad, o por capricho.

Los D. D. habían confundido extrañamente lo que es verdadera y propia causa pía con lo que no lo es, o aunque lo sea, no lo es para el efecto que se trata: los privilegios y favores que la tocan por derecho fueron extendidos tanto, cuanto ya se ha visto.

Sucede una Real declaración que reprobando sentencias arbitrarias, doy esplendor hay toda disputa y la corta para siempre. Tal es la Real Cédula del año de 9 de este siglo.

$\mathrm{Si}$ algunos de los que han votado las fuerzas, que se alegan o han escrito, en el pasado hubieran tenido tan precioso documento se habrían sacudido con más facilidad, en este punto de los interpretes que le habían enmarañado; pero olvidada o no entendida una decisión tan clara y justa, se quiere todavía, que subsistiendo aquellas proscritas opiniones se quede sin observancia y sin rigor. Aún hacen hoy más impresión aquellas distinciones de colegios fundados para estudios y los fundados para estudios de los pobres, que los que hace el Rey entre los Colegios seculares y eclesiásticos.

El Rey manda, que en los que no constare serlo, legítima y concluyentemente no tenga la jurisdicción eclesiástica la menor intervención. Hace demostrado que es mere secular el de San Francisco de Sales y que nada tiene de eclesiástico; tanto dista de poderse probar concluyentemente que lo sea.

No se deben admitir más distinciones que las hechas por la ley. Con todo se pretende otra entre los colegios piadosos y los no piadosos.

El fiscal no ignora, que es obra meritoria, de misericordia, y de piedad, fundar colegios donde se instruya y eduque santamente la 
pobre juventud, que el fin de las ciencias, el ejercicio de las virtudes morales, la enseñanza de la Teología, que mira al culto y conocimiento del supremo ser, y autor, tienen como un fin sobrenatural; pero ni esto, ni el que sean pobres los que estudian puede eximir los estudios, ni los estudiantes de la Real Jurisdicción.

Para ello era menester que mediare directamente la salud de las Almas y el peligro espiritual. Que la causa de la religión, y los estudios no pudieren de otro modo conservarse.

Si el respeto solo de la pobreza o la piedad fuese suficiente se debería decir, que el dar un buen consejo, la visita de un doliente la enseñanza de las primeras letras, atribuía jurisdicción.

Se compone bien que florezcan los estudios que los jóvenes pobres se eduquen con cuidado, con amor, y con esmero, y que no dependan de otra jurisdicción que la Real. Así se ve verificado en esta capital, y en otras partes con admirable buen suceso.

Un hospital es el verdadero teatro del horror, y la miseria. Curar y asistir con los últimos consuelos a todo género de pobres: a los viejos, enfermos, a los moribundos y estropeados es seguramente fundación, y obra más piadosa, y más humana, que un colegio ocupado por una juventud robusta o divertida, que aunque pobre, hallaría la subsistencia en el importante ejercicio de las armas, o las artes, en el útil y necesario cultivo de los campos, tal vez con mayor interés de la misma Religión y del Estado.

Sin embargo se querrá persuadir que es repugnante al Santo Concilio de Trento un colegio de Estudiantes pobres, que no se reconozca y se visite por la jurisdicción eclesiástica al mismo tiempo que se están viendo tantos y tan buenos hospitales, que no admiten más autoridad y dirección que la Real.

Se dice que los hospitales, de que se habla, están bajo la inmediata protección del Rey, lo que no sucede en el Colegio de la cuestión, que ni ha sido fundación Real, ni la Cédula de 8 de abril de 1753 en que fue concedido el permiso para su erección, le pone bajo en especial tutela.

Es verdad que el Tridentino declara a los obispos el derecho y facultad de visitar todos los Colegios y Hospitales, con tal que pidan la licencia de los Reyes, cuando estén algunos bajo su inmediata 
protección y también lo es que la inmediata protección se colige y se deduce en sentir de A. A. graves, muy difícilmente, y no de otra manera, que si así estuviere expresamente declarado.

Fue siempre grande la veneración y autoridad de los Concilios generales. En ellos se representa la Iglesia universal, el Espíritu Santo asiste a su progreso, y dirección. El que se celebró en Trento en el siglo XVI ha sido como un resumen de los anteriores en el dogma, y la más solemne prescripción de las nuevas herejías. Sus decretos sobre disciplina son muy acomodados a los tiempos, muy santos, muy convenientes y muy justos: importantes al servicio de Dios Nuestro Señor, gobierno y política eclesiástica.

El sr. Felipe II como Rey católico y verdadero hijo de la iglesia, aceptó y recibió este Concilio Sacrosanto, y quiso que fuese ejecutado y cumplido interponiendo para ello su autoridad y brazo Real.

Aquellos prelados y personas de gran doctrina, ejemplo y religión cuidaron mucho de precaver y conservar ilesos los derechos de los Príncipes y los nuestros, viendo expresamente reservados los que les correspondían por su estimable y delicada Regalía del Patronato, no dudaron declararse sus protectores especiales.

Lo supremo del Patronato Real adquirido ya por Conquista ya por fundaciones: los derechos más inseparables de la majestad, afirmados y declarados por los Sumos Pontífices, como legítimos y debidos de justicia a nuestros soberanos en premio de sus relevantes servicios a la iglesia y a la religión pedidos a la Santa Sede sino por necesidad, para la mayor quietud y sosiego de la Real conciencia: concedidos con madura previa deliberación y consejo de los cardenales, no podrán dejar de ser atendidos; conservados, renovados en un Congreso tan iluminado, que debía su principio, su existencia y pendía en su misma ejecución del celo de los Príncipes por la disciplina sana.

Son estas preeminencias Reales muy diversas, según los muy diferentes usos, costumbres y motivos. Por esto el Santo Concilio tuvo por mejor establecer indeterminadamente en el capítulo 8 de las de la seis 22, aquellos que le pareció mejor con independencia de lo que se observase en esta región o aquella, acerca de la visita de Escuelas, Cofradías, o Colegios, cumplimiento de últimas piadosas voluntades. 
Pero nunca olvidó la conservación de los supremos derechos de los Reyes: quiso su consentimiento, y Real licencia para que fuese visitado lo que hubiese tenido la fortuna de nacer, y conservarse debajo de la benéfica sombra de su inmediata, respetable protección.

Volvió a tratar en la seis, 25 , capítulo 9 de reformas del derecho de Patronato: del modo de probarle, y otros puntos graves; y teniendo la misma consideración, no extendió su reforma a los Patronatos de los Príncipes, cuyas libertades y exenciones quedaron expresamente reservadas.

No puede estar más clara su justa voluntad de no perjudicar las Regalías. Cuanto pertenece a los soberanos otro tanto quiso el Concilio conservarles. Unos hombres tan eminentes en literatura y santidad no debieron pensar, ni proceder con menos prudenciar, ilustración y rectitud.

Pero por desgracia, no opinaron así los que interpretaron y comentaron el Concilio. Apenas han dejado cosa que no hayan sustraído de la inmediata protección Real como si fuera la más dura y más odiosa, la han estrechado y restringido. Han tenido el proyecto audaz, y raro de que los Reyes litigasen ante los obispos? Cometiendo las Regalías a sus definiciones.

Hay también quien juzga, que solo esta bajo la protección inmediata de los Reyes lo que es de su Patronato específico, y por el contrario, que no está bajo su inmediata lo que solamente reconoce el Patronato Universal, de que infieren, que pueden los obispos visitar aquellas fundaciones y establecimientos que aunque por otras razones sean del Patronato Universal, no son del específico Real, porque falta la dotación de que proviene.

El fiscal no discurre así, ni fundado desde en no que los Colegios y estudios generales están bajo la inmediata protección y dependencia de los Reyes. Que la causa de Estudios es merced temporal, y a todas luces política y profana.

Las universidades están bajo la inmediata protección Real y son cuerpos mere seculares, como han probado muy [ilegible] catedráticos de Prima de Cánones en las de México, y de Salamanca, en obras bien conocidas y estimadas. 
El Colegio de San Francisco de Sales es una parte de esta universidad. Está incorporado en ella, y los que allí estudian gozan del privilegio singular de poderse graduar aquí con los cursos que allá ganan* privilegio que obtuvieron con dificultad los colegios mayores de la Universidad de Salamanca y que nunca tuvo el de Santa María de Todos los Santos.

Por esto se consideran como unidos a ella, y miembros suyos, y sin embargo de algunas particulares causas para considerarlos de naturaleza diferente, todavía se juzgaron de la misma, por aquella regla legal; de que lo que se dice del todo, con mayor razón debe decirse de sus partes.

Aquellos Colegios mayores se han creído siempre bajo la protección inmediata de los Reyes pos sus Reales gracias y favores sobre su conservación y aumento ¿y no lo estará el Colegio de San Francisco de Sales, que ha recibido de la Real piedad especiales honras y calificadas distinciones?

Aquellos colegios piden por sus constituciones cierto número de colegiales, que estén ordenados de presbíteros. Los mayores de Oviedo, y de Alcalá, que a lo menos todos sean clérigos ordenados de menores. Con todo se reputan seculares ¿y el de San Francisco, que ni por disposición de su función, ni por otra alguna pide estas notables circunstancias donde todos son, y han sido Estudiantes legos, no será mere secular?

Los Arzobispos de Toledo, Valladolid, y Salamanca no ignorarían el capítulo 8, sesión 22 de reform.

Aquellos nunca han sido visitados por los obispos sin embargo de ser rigurosas fundaciones para pobres Estudiantes ¿Este ha de ser visitado sin licencia del Rey, porque estudian en él algunos pobres?

Allá no es odiosa la protección inmediata de los Reyes, y se ha inferido sin estar expresamente declarada en sus constituciones, y estatutos: ¿acá será delito asegurar, que un Dr. Napolitano, y cuantos le siguieron, se equivocaron mucho en sostener, que esta inmediata protección no se entiende nunca, a menos de exhibirse un documento, en que clara, positiva y expresamente se declare?

*Aquí la cédula del año 56. 
¿Es posible que la sujeción honrosa a la heroica, de la suave, a la especial tutela y patrocinio de los Reyes que han sabido buscar ansiosamente los mismos obispos, y eclesiásticos, se haya convertido en odiosa y dura servidumbre?

Al Reinfestuel varón grave y religioso, y a otros muchos no se tuvo a mal, que reprobasen la Doctrina, y decisiones de la Rota, con aquel dicterio que la rota, muchas veces rota; y al Fiscal acaso se le notará que no haga el menor caso de las declaraciones de fuerza de la Chancillería de Valladolid que se citan ni de las de esta Real Audiencia que se contradicen así mismas, como puede verse del cotejo de $n^{\circ} .102$ del impreso del Dr. Larragoiti con el n .110 y que adopte una opinión perjudicial a las Regalías, esparcidas sin examen ni razón.

Y sino ¿cuál es la que se da para afirmar con tanta seguridad y magisterio, que solamente se comprende bajo la protección inmediata de los Reyes lo que verdadera y claramente consta que lo está?

Aunque la Sagrada Congregación del Concilio así lo haya declarado ¿no podrá defenderse lo contrario impunemente? ¿Porqué no se condenan aquellas opiniones de los teólogos, que no en materias sospechosas (como son seguramente las de Regalía, y extensión de jurisdicción Eclesiástica: sobre la civil, sino en materias tan escrupulosas y tan espirituales, como la validación o nulidad de matrimonio, sostienen contra la congregación, que el párroco no es un testigo simple en la administración de este sacramento: que los sacerdotes excomulgados pueden absolver en peligro de muerte de los casos reservados: que el carácter se imprime únicamente, por las órdenes sagradas, no por la tonsura?

Si un escritor recomendable y celoso de las regalías no dudó seguir la sentencia referida, el Fiscal tampoco duda separarse de la suya, transcribiendo del cardenal de Luca la razonable y curiosa distinción que suele hacerse en orden a la deferencia que se debe a los autores.

O tratan de intento la cuestión deteniéndose en su examen dando razón y causa probable del Partido que han tomado o tocan el punto transitoriamente, sin fundamentos ni disputa refiriéndose unos a otros, en cuyo último caso su autoridad de nada sirve, y es 
como un testigo, que sin haber estado presente depone sobre un lance lo que oyó.

Esta diferencia debe también aplicarse, a otra opinión rara y peregrina, que de paso, y muy superficialmente adoptó el mismo escritor, contradiciéndose: de que de la duda ¡si un hospital está o no bajo la inmediata protección? Debe el obispo conocer.

La protección inmediata de los Reyes, induce a lo menos un Patronato Universal, y aún muchos solo quieren admitirla, cuando hay patronato específico y particular; de manera, que el conocer los obispos ¡si un colegio o un hospital está o no bajo la inmediata protección del Rey? Es otra cosa, que tomar conocimiento de las Regalías, contra lo que el inusitado autor defiende en otras partes, y el fiscal ha probado (desde el $\mathrm{n}^{\circ}$. súper abundantemente).

$\mathrm{Ni}$ es menos de admirar, que se haya querido equivocar y confundir lo que es protección inmediata de los Reyes con su patronato específico Real de manera, que sean proposiciones convertibles. Este colegio es de su inmediata protección: luego es de su Patronato específico: y al contrario. No es de Patronato Real específico: luego no es de Real inmediata protección.

Se ha insinuado aunque muy ligeramente, lo que en esto suele haber, y los efectos diferentes, según los varios casos; ahora bastará advertir, que la inmediata protección Real puede muy bien darse sin otro Patronato, que el Universal; pero este Patronato produce regularmente la Real inmediata protección.

El Colegio de Santa María de Todos los Santos de esta capital, y los mayores de Valladolid, y Salamanca están como ya se ha visto bajo la inmediata protección Real en medio de haber sido dotados, fundados, erigidos por personas particulares, y prelados, y por lo mismo, y no haber intervenido cesión de este derecho, sin que sean, ni habían sido nunca del Patronato específico del Rey. Luego no se requiere necesariamente para que pueda tener lugar su inmediata protección.

Ni hace al caso, que el Colegio de San Francisco de Sales no sea mayor como los otros. Esta gracia o cualidad, no puede mudar su esencia en nada, y así como se ha probado (en el nº.) que sin ascenso de los Reyes, no pueden ni los papas, hacer que aquello que es de su 
jurisdicción, en adelante no lo sea: así tampoco nuestros soberanos; que muy distantes de privar a la iglesia de sus franquezas y exenciones se las han concedido largamente pudieran haber dispensado mayorías para hacer de su inmediata protección lo que antes no lo fuese, privando al Cabildo del derecho de visita y otros que le da la constitución de Santos.

Si la gracia apostólica concedida para ampliar o mejorar algún derecho secular, se deja usar como temporal acomodándose a su naturaleza ¿no sería rigor y absurdo que una gracia Real dispensada a favor de un establecimiento sujeto y dependiente por su creación o por otra cualquiera causa, de la potestad eclesiástica obrase el violento, y no querido efecto de arrancarle de sus manos para colocarle en otras?

Los efectos de la mayoría, no son por cierto substraen los colegios a que se concede del conocimiento de la jurisdicción eclesiástica perjudicándola y disminuyéndola.

El de la Santa María de Todos los Santos en representación de 28 de julio de 1691 solicitó de S. M. se dignasen declararle Colegio mayor con los mismos privilegios, que gozan los de España.

Pidió el consejo informes y conviniendo V. A. el Virrey Conde de Galve, el cabildo eclesiástico, el secular las religiones de Santo Domingo, San Francisco, San Agustín, la Compañía de Jesús, la Merced calzada y el Carmen descalzo en que era el más antiguo, más útil, de mayor nombre y grado, y una de las primeras y más graves comunidades de este reino, por las particulares causas que expusieron, hizo consulta a S. M. en 15 de marzo de 1700 , con lo que se conformó, concediéndole la honra de Colegio Mayor, ejecutándole en las prerrogativas y privilegios con el mayor de San Felipe de Lima, sin diferencia alguna: y a consecuencia de esta Real Merced se expidió la Cédula y título en 15 de abril de 1700 que trujo a esta capital su apoderado el Dr. Don Juan de Castorena.

Son bien publicas las ruidosas consecuencias de esta Real declaración: la inteligencia que le dio esta Real Universidad: los recursos al consejo y al mismo soberano, pero conduce notar tan solamente, que toda esta disputa dimanó de comprender diferentemente los privilegios de la mayoría. 
El Colegio solicitaba que sus alumnos fueren graduados con mitad de propinas, y que después las percibiesen por entero: Cátedra y conciliatura como gozaba el San Felipe. Estas son las prerrogativas que se consideraron propias de la mayoría, y las que en un Real Decreto de 23 de octubre de 1707 se dicen prerrogativas anexas precisamente competentes y físicamente inseparables del Título de Colegio Mayor que se le concedió en 15 de abril de 1700.

Estas las que disfruta el Mayor de Maese Rodrigo y los Mayores de San Ildefonso de Alcalá, los de San Bartolomé, Cuenca, Arzobispo, Oviedo, y Santa Cruz, y las que gozan el de San Felipe, por Mayor, como se prueba de que siempre, que las leyes hablan de ellas, le llaman mayor, no dándole este título cuando le nombran, tratando de otros puntos.

No disputo ni litigó más prerrogativas al Colegio de Santa María de Todos los Santos y es de creer, que a la manera que la misma universidad, que antes había cooperado a su solicitud, no dejó de oponérsele después y con dureza, cuando contempló seguírsele perjuicio de la gracia: así también, si el Título de Colegio mayor hubiera disminuido o quitado al M. R. Arzobispo al cabildo o a otro alguno sus derechos no habrían dejado de reclamarlos, y de defenderlos.

Aquellos recursos y contiendas sobre las prerrogativas de la mayoría duraron en el Consejo por lo menos hasta el año de 710, y estaban en la mayor fermentación por el de nueve en que se expidió la Real Cédula del 11 de junio tantas veces referida, y sea el que fuere, el suceso, que la motivo, la decisión excluye toda intervención de la jurisdicción arzobispal, precisamente porque el Colegio de Todos Santos es mere secular.

Si la mayoría, hubiese sido la causa de excluirla, pudo haberse así expresado con las mismas palabras, o con menos en un tiempo en que se tenía muy presente esta circunstancia; y merced recientemente concedida, y de cuyos efectos se estaba entonces disputando.

No se dice, que el M. R. Arzobispo no deba tener intervención en el gobierno económico del Colegio de Santos, porque sea Mayor, sino por que es mere secular, con que el Colegio de San Francisco de Sales, que es mere secular, aunque no sea Mayor dependerá en su gobierno económico de la potestad civil. 
La Real Cédula de 11 de junio de 709 declara, que es perjudicial a la Regalía Suprema del Patronato Universal, que el gobierno de los Colegios mere seculares, no sea privativo del conocimiento de los magistrados seculares. Para que no quede duda, ni se quiera exceptuar algo, añade, que la jurisdicción eclesiástica en nada puede entrometerse en los Colegios que no sean eclesiásticos legítima y concluyentemente. Sea el que fuere el recurso y caso que dio motivo al despacho de esta Cédula ¿podrá negarse su general disposición? ¿Habrá quien sostenga todavía, que la jurisdicción eclesiástica puede entrometerse en algo en el gobierno económico de los Colegios mere seculares?

El decreto de 22 de diciembre del año próximo pasado comprende el gobierno económico, y académico del Colegio de San Francisco: número de sus colegiales: catedráticos, cátedras, y autores que se explican: fondos, rentas, libros de cargo de cargo y data, recibo y gasto ¿y una jurisdicción, que no puede entrometerse en el gobierno económico de este Colegio, ni en nada, podrá conocer de tanto, o por mejor decir, de todo?

El M. R. Arzobispo de México, que no puede tomar conocimiento del gobierno económico del Colegio de Santa María de Todos Santos ¿podrá rever sus cuentas, pedir razón de sus fondos, examinar como se invierten? No debiendo entrometerse en nada ¿podría por motivo de piedad visitar sus libros, registrar sus arcas, cotejar el manejo y la conducta de sus individuos, con sus Constituciones?

¿Hubo algún prelado que interpretase la Cédula citada como decisiva y solamente terminada al particular recurso del colegial don Tomás Montańo? ¿Qué distinguiere de los casos en que el colegio otorgue un contrato, cometa un delito: en que el rector haga injusticia a alguno de sus individuos, explicándole sin causa o privándole sin ella de la cátedra, conciliatura o de otra cosa que le pertenezca por estatuto, o por derecho; y entre aquellos, en que se trate del cumplimiento de sus constituciones administración de sus fondos, desempeńo de sus cargas?

De tantos y tan grandes hombres, como han gobernado esta Santa Iglesia Metropolitana en todo el siglo ‘hubo alguno que hubiese querido tomar intervención, ni en lo uno ni en lo otro? ¿№ se 
viola igualmente la constitución, la intención y la voluntad del fundador, cuando aflige, o castiga el rector a quien no debe, que cuando disimula, o no cumple ni ejecuta lo que ha dispuesto aquel en otros puntos económicos? Si los de visita no fueron comprendidos en aquella Real determinación ¿A que fin una cédula especial del Rey para que el M. R. Arzobispo actual pueda visitar por una vez el Colegio de Santa María de Todos Santos?

No por esto deja el fiscal de confesar con ingenuidad y buena fe, que el difunto R. obispo de Valladolid y su visitador tuvieron juntos motivos para proceder, según han procedido las repetidas, quietas visitas anteriores: el capítulo del santo concilio tridentino: otras muchas consideraciones graves, a que el fiscal ha satisfecho; el reconocimiento reciente, y reiterado en este mismo asunto de la congregación de San Felipe a la jurisdicción episcopal; la futilidad, y ningún momento de la única excepción opuesta sobre conexión, accesión y dependencia de la visita del Colegio con la de su interior gobierno, fueron robustos y legales fundamentos para haber intentado visitar el Colegio de San Francisco de Sales imitando a sus antecesores.

Las Cédula Reales pueden muy bien ser ignoradas a diferencia de las leyes y pragmáticas sanciones, que se recopilan, publican. Una decisión antigua, sepultada entre la oscuridad y el polvo de un archivo, sobre cuyo contenido, puede ser, no se haya suscitado desde su expedición, recurso, ni dificultad alguna, solo por casualidad puede llegar a la noticia de las personas a que no fue comunicada.

El fiscal se persuade del gran tiento con que se procedió siempre el difunto R. obispo en las materias jurisdiccionales de su fidelidad, miramiento y singular cuidado en no perjudicar ni ofender las Regalías que si en lugar de la débil excepción, que se le opuso, se le hubiera dado luz de aquella, no habría seguramente dado un paso sin ponerse antes muy de acuerdo con el Vice Patronato.

Es también notoria a B. A. la literatura, la suavidad de genio y el modo de pensar de su visitador general el arcediano don Joseph Pérez Calama. El fiscal que le conoce, no duda asegurar que su ánimo estuvo muy distante de dar el más ligero golpe a aquel señorío Real y alta mayoría que en esta respuesta se defiende. 
En ellas se han tocado con la concesión posible los gravísimos puntos que comprende este proceso complicado.

Se ha hecho extracto de los principales hechos, y de los fundamentos de las partes que han recurrido a V. A. se ha dicho sobre ellos lo que ha parecido más conforme a las leyes y a los libros, libres del espíritu de partido y prevención. Se han manifestado los principios generales de los recursos de fuerza en no otorgar y de conocer y proceder: porque no debe ser auxiliada la jurisdicción episcopal: porque no se debe dar traslado de su instancia a la congregación de San Felipe: porque en este negocio no puede tener lugar la declaración de fuerza: porque debe ser remitido a vuestro Exmo. Virrey, como a la persona en quien reside el Vice Patronato. Como el Colegio de San Francisco de Sales, aunque no sea del Real Patronato específico, es del Patronato universal de S. M. y de su Real inmediata protección.

También se ha ilustrado y aplicado oportunamente a la presente controversia la Real Cédula de 11 de junio de 1709 cuya decisión suprema se dio y tuvo lugar en el Colegio de Santa María de Todos Santos, fundación para aquéllos jóvenes que no pueden estudiar por tenuidad de facultades según expresa en el prólogo el mismo fundador, nombrándole asilo de estudiantes pobres, afirmando en la tercera de sus constituciones, que no es otra su intención y sus deseos que atender y ayudar la pobreza de los escolares.

Se ha desvanecido y disipado la densa nieve de dificultades, que preparaba a la inteligencia de la Cédula, y de lo que está mandado en las leyes de Castilla respecto de otros colegios también fundados para pobres, la poca reflexión de muchas plumas, que confundieron y no explicaban bien los derechos legítimos que en las causas pías corresponden a la jurisdicción episcopal.

Se ha hecho por fin ver como el Colegio de San Francisco de Sales, aunque no sea mayor, puede ser, y es colegio mere secular, y que esto basta para que sea en todo independiente de aquella jurisdicción, que no puede intervenir en nada en los colegios que no sean eclesiásticos, legítima y concluyentemente.

El fiscal con estos fundamentos y con los demás que expondrá a la vista pide a V. A. se sirva remitir este negocio del Exmo. Señor Vice Patrono, donde protesta promover lo justo y más conforme a 
la Regalía para dar por fin a este colegio reglas solemnes y formales estatutos: a sus rentas seguridad separación y buen manejo: a sus individuos, doctrina pura y cristiana educación.

Asimismo pide el fiscal, se sirva V. A. devolver al venerable Dean y cabildo sede vacante de Valladolid de Michoacán el proceso venido en virtud de la Real provisión de autos diminutos declarando que no vienen en estado y costas.

Además de no tener conexión alguna con el otro expediente de visita de Colegio, el de visita de gobierno interior de la Congregación de San Felipe de la villa de San Miguel el Grande; como que no es entre Jueces Eclesiásticos que disputen entre sí sobre conocimiento de alguna causa o territorio, ni sobre contravención a decisiones del Concilio, sólo podría venir a V. A. siendo Eclesiásticos y entre Eclesiásticos por denegada apelación la que no hubo, ni pudo haber tampoco sin pronunciamiento de sentencia.

Finalmente no debe el fiscal desentenderse de la sentida justa queja del venerable dean y cabildo sede vacante sobre la irreverencia en que ha incurrido el Alcalde ordinario de aquella villa don Miguel de Unzaga faltando a todos los sentimientos de atención de política y de caridad con su prelado.

V. A. distingue a los obispos: los ampara y los venera, como sucesores inmediatos de los Apóstoles en el gobierno espiritual de la iglesia militante, y no ha de ver con indiferencia que tan sagrada dignidad colocada en la persona respetable de un varón tan docto y ejemplar se haya querido ofender, y atropellar por resentimientos de particulares conexiones, en el crítico momento de su última agonía.

El fiscal no halla castigo para impiedad y delito tan enorme. V. A. impondrá el que le corresponda con su justificación inalterable. México, y marzo 24 de 1782. Posada. Fin. 